\title{
Cavitand-Decorated Silicon Columnar Nanostructures for the Surface Recognition of Volatile Nitroaromatic Compounds
}

Cristina Tudisco, ${ }^{\dagger, \|}$ Alessandro Motta, ${ }^{\ddagger}$ Tahnie Barboza, ${ }^{\S}$ Chiara Massera, ${ }^{\S}$ Antonino E. Giuffrida, ${ }^{\dagger}$

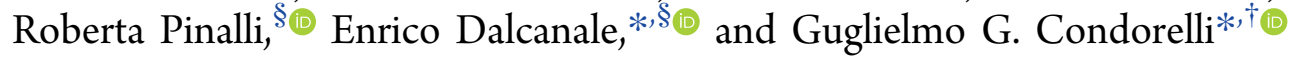

${ }^{\dagger}$ Dipartimento di Scienze Chimiche, Università di Catania, and INSTM UdR Catania, V.le A. Doria 6, 95125 Catania, Italy

${ }^{\ddagger}$ Dipartimento di Chimica, Università degli Studi di Roma “La Sapienza” and INSTM UdR Roma, P.le A. Moro 5, 00185 Roma, Italy

${ }^{\S}$ Dipartimento di Scienze Chimiche, della Vita e della Sostenibilità Ambientale, Università di Parma and INSTM UdR Parma, Parco Area delle Scienze 17/A, 43124 Parma, Italy

\section{Supporting Information}

ABSTRACT: Nanocolumnar Si substrates (porous silicon (PSi)) have been functionalized with a quinoxaline-bridged (EtQxBox) cavitand in which the quinoxaline moieties are bonded to each other through four ethylendioxy bridges at the upper rim of the cavity. The receptor, which is known to selectively complex aromatic volatile organic compounds (VOCs) even in the presence of aliphatic compounds, has been covalently anchored to PSi. The larger surface area of PSi, compared to that of flat substrates, allowed one to study the recognition process of the surface-grafted receptors through different techniques: Fourier-transform infrared spectroscopy, thermal desorption, and X-ray photoelectron spectroscopy. The experiments proved that surface-grafted cavitands retain the

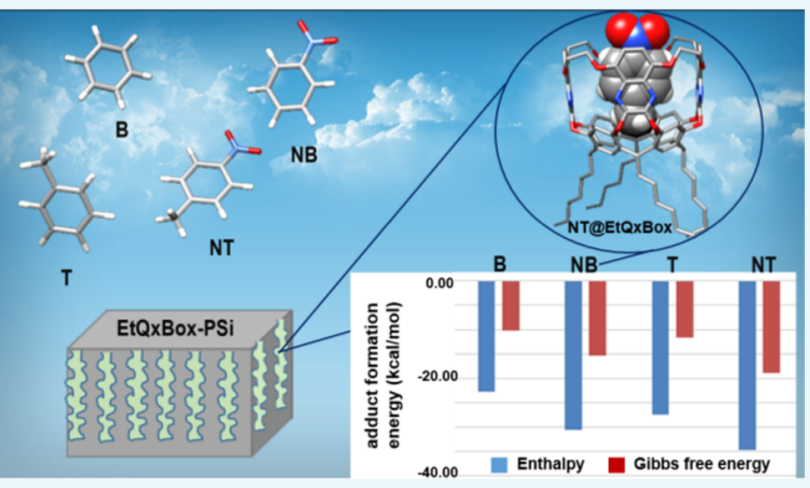
recognition capability toward aromatic VOCs. In addition, the affinities of EtQxBox for various aromatic compounds (i.e., benzene, toluene, nitrobenzene, and p-nitrotoluene) have been studied combining density functional theory computations and thermal desorption experiments. Computational data based on the crystal structures of the complexes indicate that this cavitand possesses a higher affinity toward aromatic nitro-compounds compared to benzene and toluene, making this receptor of particular interest for the detection of explosive taggants. The results of computational studies have been validated also for the surface-grafted receptor through competitive recognition experiments. These experiments showed that EtQxBox-functionalized PSi can recognize nitrobenzene in the presence of a significant excess of aromatic vapors such as benzene $(1: 300)$ or toluene $(1: 100)$.

\section{INTRODUCTION}

The detection of volatile nitroaromatic compounds is an area of active research, particularly regarding environmental monitoring and social security. ${ }^{1}$ Among nitroaromatics, nitrobenzene (NB) and 4-nitrotoluene (NT) are molecules of particular interests because $\mathrm{NB}$, which is widely used in organic industries, is considered a highly polluting substance due to its toxicity, carcinogenicity, and biological persistence, ${ }^{2}$ whereas NT is an explosive taggant. ${ }^{3}$

Previous papers reported the detection of these nitroaromatic compounds adopting different analytical techniques such as liquid chromatography/mass spectrometry, ${ }^{4-6}$ spectrophotometry, ${ }^{7}$ chromatography, ${ }^{8}$ fluorescence quenching methods, ${ }^{9,10}$ electrochemical methods, ${ }^{11}$ surface-enhanced Raman spectroscopy, ${ }^{12,13}$ and using various organic and inorganic materials such as metallic nanoparticles, ${ }^{2,14}$ metalorganic frameworks, ${ }^{15-17}$ polymers, ${ }^{18}$ carbon nanostructures, ${ }^{19,20}$ and self-assembled monolayers. ${ }^{21,22}$ General overviews of nitroaromatic detection approaches can be found in some recent reviews. ${ }^{23-25}$ Although all of these methods allow the detection of $\mathrm{NB}$ at low concentrations, they often require complex instruments and time-consuming sample preparations and, in some cases, suffer from low selectivity or lack of reversibility. On the contrary, detection methods based on supramolecular receptors (such as quinoxaline-bridged and iptycene-roofed cavitands for aromatic volatile organic compounds (VOCs) or higher iptycenes for nitrocompound detection $^{26-28}$ ) have recently been explored as alternatives to classical approaches for a fast and easy recognition of the presence of aromatic contaminants. ${ }^{29-35}$ Conformationally mobile quinoxaline-based cavitand (QxCav, Chart 1$)^{36}$ showed remarkable selectivity and sensitivity for the detection of benzene, toluene, ethylbenzene, and xylenes (BTEX) in air. ${ }^{29}$ The complexation properties of this receptor are due to the

Received: May 16, 2018

Accepted: July 19, 2018

Published: August 15, 2018 
Chart 1. Chemical Structures of the Cavitands Discussed in this Study
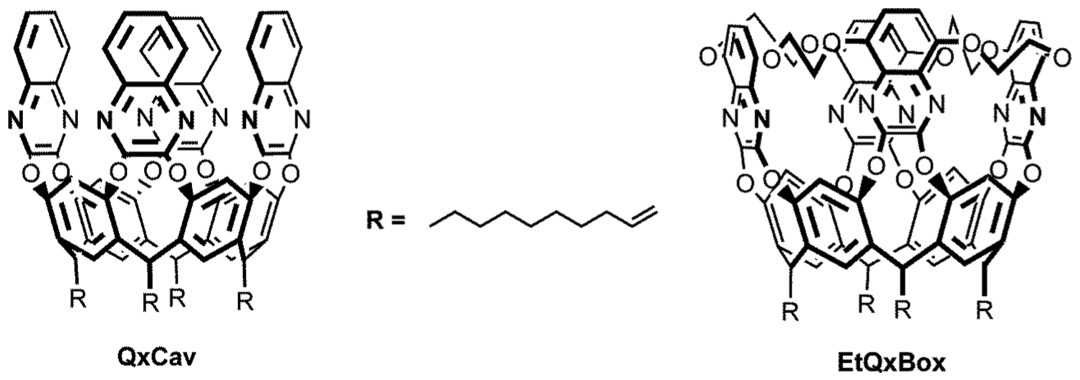

Scheme 1. Synthesis of EtQxBox

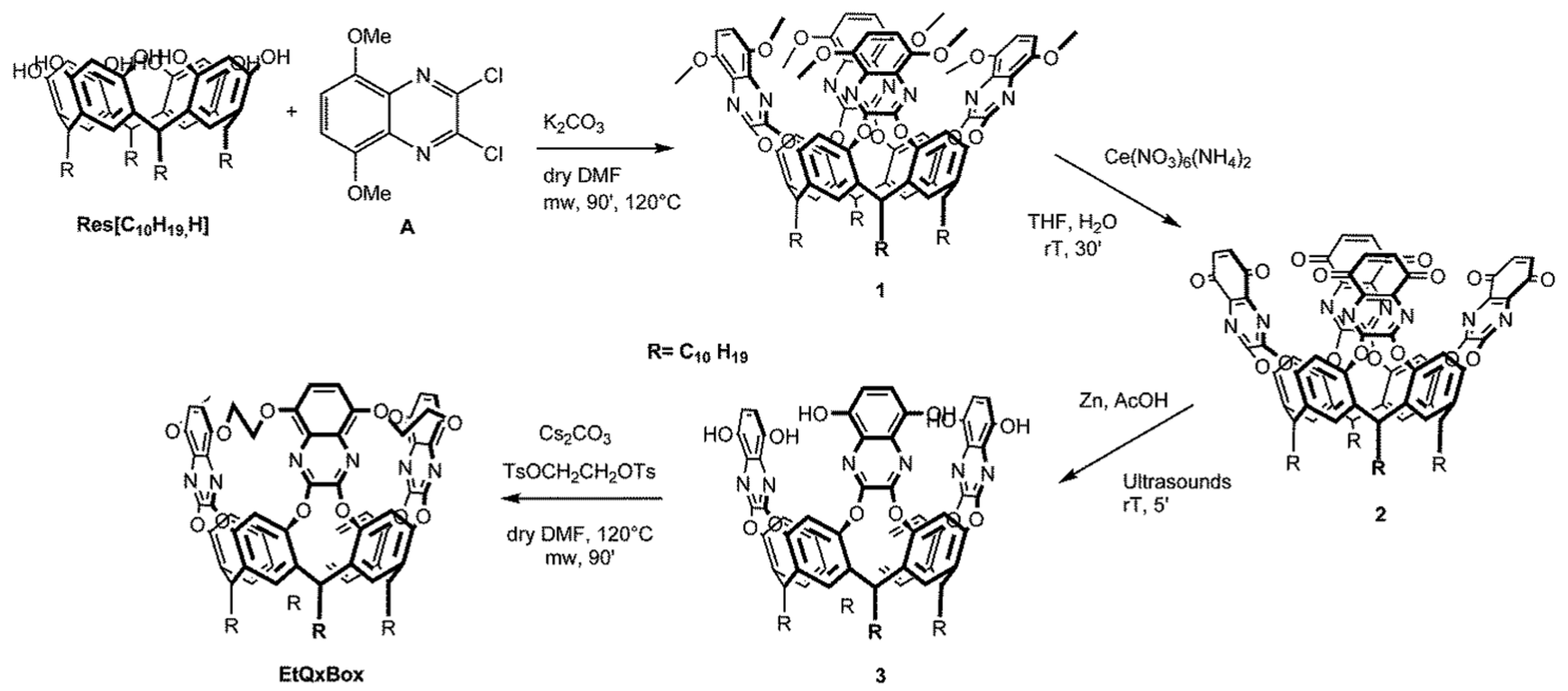

presence of a deep, hydrophobic cavity capable of engulfing aromatic rings, interacting with them via a set of $\mathrm{CH} \cdots \pi$ and $\pi$ stacking interactions. ${ }^{33}$ These complexation proprieties are retained after the covalent anchoring of this receptor on different surfaces (i.e., $\mathrm{Si}$ and $\mathrm{ZnO}$ ). ${ }^{37,38}$ Recently, a new conformationally rigid quinoxaline cavitand (EtQxBox) delimited by four quinoxaline walls linked via ethylendioxy bridges (Chart 1) was synthetized. ${ }^{39}$ This new receptor exhibits an enhanced trapping efficiency for BTEX compared to the parent QxCav receptor in air. Moreover, the conformational rigidity of this cavitand maximizes the binding of toluene, ethylbenzene, and xylenes (TEX) with respect to benzene by increasing the number and strength of their synergistic $\mathrm{CH} \cdots \pi$ interactions. $^{39}$

However, the use of cavitands as bulk material limits the degree of miniaturization achievable and, in addition, it can affect the receptor selectivity due to residual nonspecific adsorptions at the solid-gas interface. On the contrary, one of the limitations of the use of monolayers on flat substrates is related to the low surface area and, in turn, to the low amount of material involved in the recognition process, thus jeopardizing sensitivity. A possible solution to these limitations is the deposition of receptor monolayers on high surface area substrates. $^{41-43}$

Herein, we report on the covalent anchoring of a specifically designed EtQxBox cavitand to columnar porous silicon (PSi) through hydrosilylation of the undecylenic feet decorating the lower rim of the receptor. The high surface area of PSi allowed us to study the heterogeneous recognition process of the surface-grafted receptors versus aromatic analytes through different analytical techniques: Fourier-transform infrared spectroscopy (FTIR), thermal desorption, and X-ray photoelectron spectroscopy (XPS). An unprecedented selectivity of EtQxBox@PSi toward nitroaromatic compounds compared to benzene and toluene has been assessed and rationalized combining thermal desorption experiments with a density functional theory (DFT) approach.

\section{RESULTS AND DISCUSSION}

Material Synthesis and Characterization. The desired cavitand was prepared following a step-by-step synthetic approach, starting from resorcinarene Res $\left[\mathrm{C}_{10} \mathrm{H}_{19}, \mathrm{H}\right]$ (Scheme 1) presenting four terminal double bonds at the lower rim, essential for the grafting of the cavitand onto porous silicon.

Resorcinarene Res $\left[\mathrm{C}_{10} \mathrm{H}_{19}, \mathrm{H}\right]$ was obtained from the standard condensation of resorcinol and undecylenic aldehyde in acidic conditions; ${ }^{44}$ Res $\left[\mathrm{C}_{10} \mathrm{H}_{19}, \mathrm{H}\right]$ was reacted in anhydrous conditions with four equivalents of 2,3-dicloro5,8-dimethoxyquinoxaline $\mathbf{A}$, in a microwave reactor, in the presence of $\mathrm{K}_{2} \mathrm{CO}_{3}$ as the base and dimethylformamide (DMF) as the solvent, affording the octamethoxy-quinoxaline cavitand $\mathbf{1}$ in good yields. The subsequent reaction step was the deprotection of the methoxy groups to have four couples of neighboring free $\mathrm{OHs}$ on the quinoxaline ring for cavity rigidification by the introduction of four ethylendioxy bridges. 

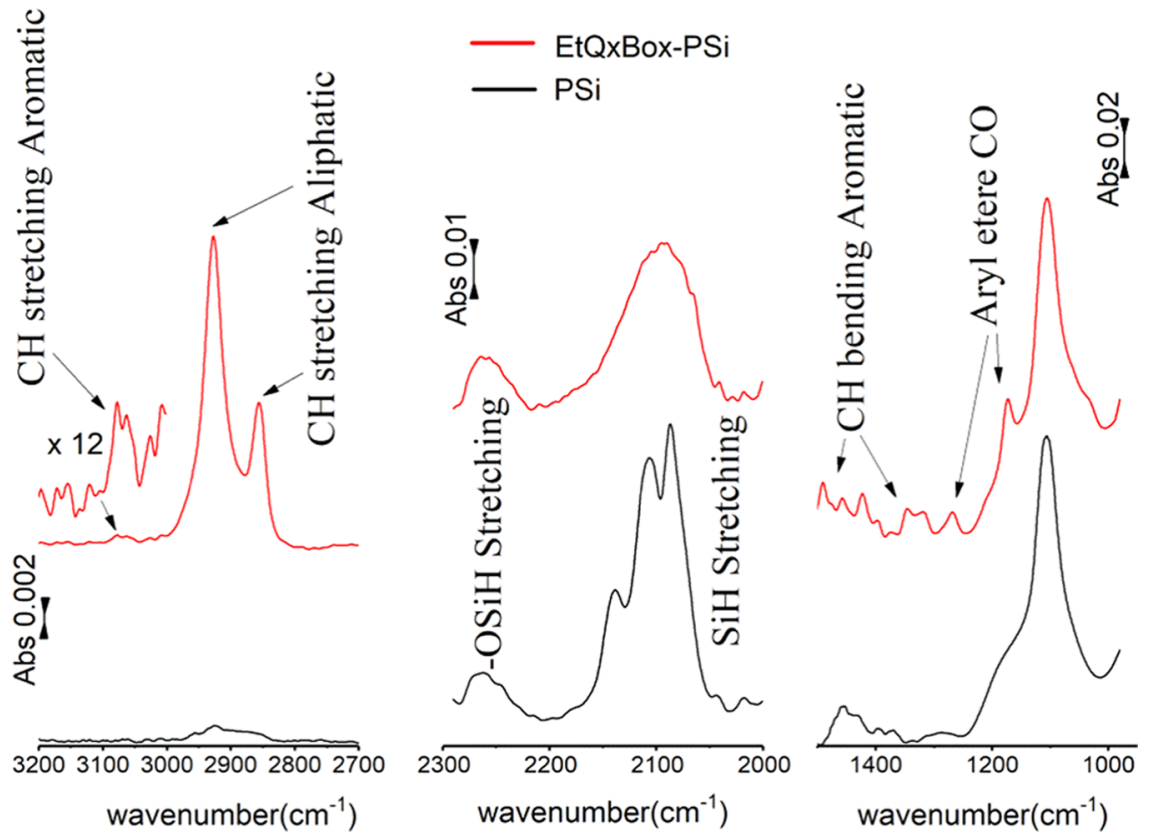

Figure 1. FTIR spectral regions in the $3200-2700 \mathrm{~cm}^{-1}$ (left), $2300-2000 \mathrm{~cm}^{-1}$ (middle), and $1500-950 \mathrm{~cm}^{-1}$ (right) ranges of bare PSi (black line) and EtQxBox-PSi (red line).

In a previously reported procedure, ${ }^{39}$ the deprotection of the methoxy groups of quinoxaline was performed by aluminum trichloride in anhydrous toluene. In this case, the presence of the four double bonds at the lower rim of the resorcinarene is not compatible with the use of $\mathrm{AlCl}_{3}$ as a deprotecting agent. Therefore, new deprotection conditions were elaborated to preserve the presence of the four double bonds. The deprotection of cavitand $\mathbf{1}$ was performed in two steps. The first one consisted in the oxidative elimination of the eight methoxy groups by cerium ammonium nitrate, leading to the tetraquinone-quinoxaline cavitand 2 . Crude $\mathbf{2}$ was purified by column chromatography, and the deprotection was confirmed through ${ }^{1} \mathrm{H}$ NMR by the disappearance of the methoxy signal. Owing to its low stability, cavitand $\mathbf{2}$ was immediately used in the next step, which consisted in the reduction of the quinone groups by sonication in the presence of metallic zinc (reducing agent) and acetic acid (proton donor) to give cavitand 3 . The final reaction step was the rigidification of the cavitand via introduction of four ethylendioxy groups bridging the eight $\mathrm{OH}$ moieties at the upper rim. Cavitand 3 was reacted in dry conditions under microwave irradiation with ethylene glycol ditosylate in the presence of anhydrous $\mathrm{Cs}_{2} \mathrm{CO}_{3}$ as base and dry DMF as solvent, affording the desired EtQxBox cavitand in $50 \%$ yield (Figure $\mathrm{S} 1$ ).

PSi functionalization was performed through thermal hydrosilylation of the EtQxBox terminal double bonds at the lower rim, following a reported procedure. ${ }^{45}$ FTIR and XPS were carried out to characterize porous silicon slides (PSi) functionalized with EtQxBox receptors (EtQxBox-PSi). Figure 1 compares the following FTIR spectral regions of bare PSi (black line) and EtQxBox-PSi (red line): (a) the C$\mathrm{H}$ stretching region between 3200 and $2700 \mathrm{~cm}^{-1}$; (b) the Si$\mathrm{H}$ stretching region between 2300 and $2000 \mathrm{~cm}^{-1}$; and (c) the region between 1500 and $950 \mathrm{~cm}^{-1}$, which contains $\mathrm{SiO}_{x}$ and $\mathrm{C}-\mathrm{O}$ stretching vibrations. The EtQxBox-PSi spectrum shows two strong bands due to the $\mathrm{CH}_{2}$ symmetric $\left(\nu_{\mathrm{s}}\left(\mathrm{CH}_{2}\right)\right)$ and antisymmetric $\left(\nu_{\mathrm{a}}\left(\mathrm{CH}_{2}\right)\right)$ stretches at 2852 and $2928 \mathrm{~cm}^{-1}$ and a lower band at $3050 \mathrm{~cm}^{-1}$ assigned to the aromatic $\mathrm{C}-\mathrm{H}(\nu(\mathrm{CH}))$ stretches of the cavitand. ${ }^{45}$ The presence of these bands, combined with the absence of the analogue ones in the PSi spectrum, indicates that the receptor is grafted to the PSi surface. In the spectrum of bare PSi, three distinct signals at 2085, 2107, and $2267 \mathrm{~cm}^{-1}$, due to $\mathrm{SiH}$, $\mathrm{SiH}_{2}$, and $\mathrm{SiH}_{3}$ stretches, respectively, are present. ${ }^{46}$ After EtQxBox anchoring, these SiHx peaks broaden slightly and decrease, leading to a single broad band, as a result of the hydrosilylation reaction, which causes the partial replacement of $\mathrm{Si}-\mathrm{H}$ terminations with $\mathrm{Si}-\mathrm{C}$ bonds. In addition, the low broad band at $2251 \mathrm{~cm}^{-1}$ observed in the EtQxBox-PSi spectrum can be assigned to the $\mathrm{OSi}-\mathrm{Hx}$ stretches of the partially oxidized silicon substrate. ${ }^{47}$ The $1500-950 \mathrm{~cm}^{-1}$ region of the EtQxBox-PSi spectrum shows two bands at 1172 and $1272 \mathrm{~cm}^{-1}$ attributed to the aromatic $\mathrm{C}-\mathrm{O}$ bond of the ethylendioxy bridges. In addition, the EtQxBox-PSi spectrum shows also some features in the $1500-1300 \mathrm{~cm}^{-1}$ region associated with the breathing modes of the aromatic ring. All of these features are not detectable in the PSi spectrum.

XPS characterization gives further indication of the success of the anchoring process. XPS C 1s and N 1s spectral regions of PSi and EtQxBox-PSi samples are shown in Figure 2. The C $1 \mathrm{~s}$ spectrum of PSi (Figure 2a) mainly consists of a component centered at $285.0 \mathrm{eV}$ due to adventitious carbon and a low shoulder around $286.0 \mathrm{eV}$ due to oxidized adventitious carbons. The EtQxBox-PSi spectrum (Figure 2b) consists of three main components. The first component, centered at $285.0 \mathrm{eV}$, represents aliphatic and aromatic hydrocarbons, whereas the second one, centered at $286.5 \mathrm{eV}$, can be attributed to the carbon in the cavitand phenyl ring bonded to one oxygen. Note that the possible formation of $\mathrm{Si}-$ $\mathrm{O}-\mathrm{C}$ groups due to the reaction between $\mathrm{Si}-\mathrm{H}$ and $\mathrm{Si}-\mathrm{OH}$ termination with oxidized carbon species can contribute to this latter component. The third component at $287.6 \mathrm{eV}$ is due to quinoxaline carbons that bond both oxygen and nitrogen 


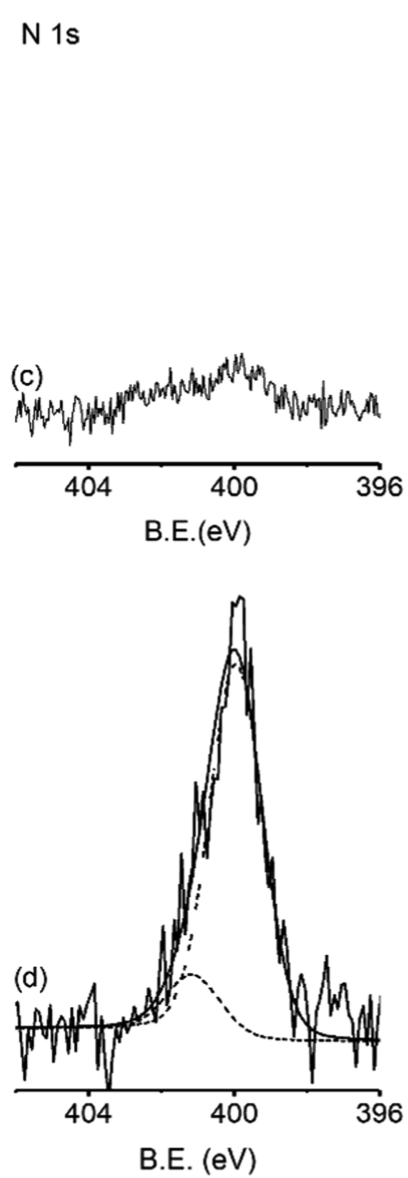

Figure 2. XPS C 1s (left) and N 1s (right) spectral regions of PSi (a, c) and EtQxBox-PSi (b, d) samples.

atoms. The $\mathrm{N}$ 1s spectrum of EtQxBox-PSi (Figure 2d) consists of a main band centered at $399.9 \mathrm{eV}$ due to the nitrogens of the quinoxaline rings. ${ }^{48} \mathrm{~A}$ much less intense side component at $401.1 \mathrm{eV}$ could be due to protonated $\mathrm{N}$ atoms or forming $\mathrm{H}$ bonds. The presence of these bands, combined with the absence of the analogue signals on PSi (Figure 2c), is a clear evidence of the grafting of EtQxBox on the surface.

Complexation Studies. Crystal Structure of NT@EtQxBox. To evaluate the inclusion ability of EtQxBox toward nitroaromatic compounds, the crystal structure of complex NT@EtQxBox·10DMSO was determined by single-crystal Xray diffraction methods (Figure S2). This complex was obtained by slow evaporation of a dimethyl sulfoxide (DMSO) solution of hexyl-footed EtQxBox ${ }^{39}$ and NT from a 1:1 stoichiometric ratio mixture. Crystallographic details for the structures are reported in the Supporting Information, Table S1.

Different views of the molecular structure are shown in Figure 3, whereas geometrical details of the interactions responsible for the complex formation are given in Figure S3 and Table S2. NT enters the cavity with the methyl group, which interacts with the aromatic walls at the lower rim of the host via two $\mathrm{C}-\mathrm{H} \cdots \pi$ interactions, dictating the orientation of the guest into the cavity. These interactions are strengthened by the presence of the nitro substituent on the aromatic ring, which renders the methyl group more "acidic". The guest is further stabilized by the presence of two bifurcated $\mathrm{C}-\mathrm{H} \cdots \mathrm{N}$ weak $\mathrm{H}$ bonds involving the aromatic hydrogen atoms ortho to
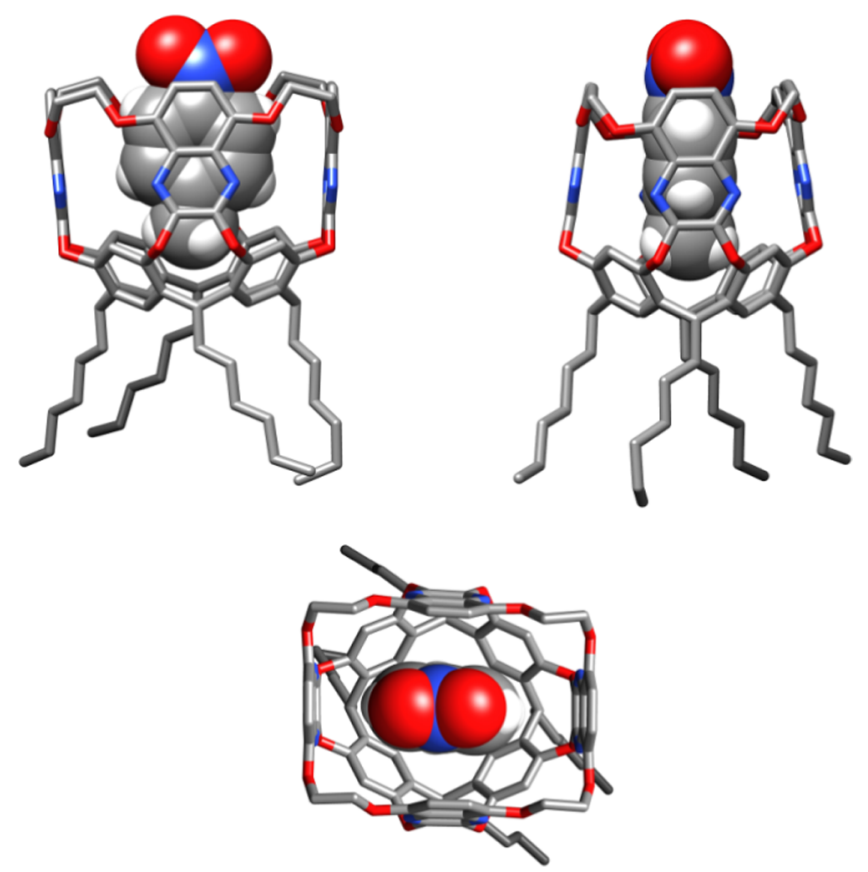

Figure 3. Side and top views of the molecular structure of NT@ EtQxBox. Color code: C, gray; O, red; N, blue. Hydrogen atoms and solvent molecules have been omitted for clarity. The guest is represented in space-filling mode.

the methyl group and the nitrogen atoms of two quinoxaline rings (see Figure S3 and Table S2). The nitro group does not interact with the cavity rim.

Nitroaromatic Vapor Complexation by EtQxBox-PSi. The affinity of the cavitand-grafted silicon surfaces toward aromatic compounds has been evaluated by exposing EtQxBox-PSi to either NB (about $30 \mathrm{~Pa}$ ) or NT (about $15 \mathrm{~Pa}$ ) vapors calculated according to the Antoine equation. ${ }^{49}$ The detection of the surface-complexed molecules was performed using both XPS and FTIR techniques. In addition, a control reference surface (Ref-PSi) was prepared and similarly exposed to the nitroaromatic vapors. Ref-PSi consisted of a PSi surface functionalized with an inactive organic monolayer formed by a mixture $(4: 1)$ of 1 -dodecene and a linear naphtyridine, the 2,7-diamido-1,8-naphthyridine. ${ }^{50}$ The mixed alkene/naphtyridine monolayer was chosen for its elemental composition $(\mathrm{C} /$ $\mathrm{N} / \mathrm{O}=14: 1: 0.5)$ similar to that of EtQxBox $(\mathrm{C} / \mathrm{N} / \mathrm{O}=$ 13.5:1:2).

Figure $4 \mathrm{a}$ shows the evolution of EtQxBox-PSi FTIR spectra in the $1800-1200 \mathrm{~cm}^{-1}$ range after exposure to NB or NT vapors. The spectrum of Ref-PSi after NB exposure has been reported as reference. The spectra of EtQxBox-PSi after exposure to the analytes show the characteristic bands at 1345 and $1523 \mathrm{~cm}^{-1}$ associated with the asymmetric and symmetric $\mathrm{N}-\mathrm{O}$ stretching of $\mathrm{NO}_{2}$, respectively. These bands are absent in the Ref-PSi spectrum under the same conditions (Figure 4a bottom), indicating that surface-bound EtQxBox is needed for the recognition and that nonspecific interactions can be neglected.

The reversibility of the complexation process was then evaluated through the FTIR monitoring of the intensity variation of $\mathrm{NO}$ stretches during $\mathrm{NB}$ adsorption/desorption cycles. These cycles were obtained through sample exposure to $\mathrm{NB}$ vapors (adsorption), followed by a mild treatment at $80{ }^{\circ} \mathrm{C}$ under $\mathrm{N}_{2}$ flushing for $20 \mathrm{~min}$ (desorption). The decrease of the 
(a)

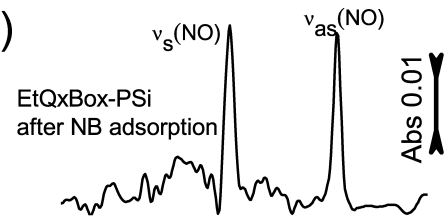

EtQxBox-PSi

after NT adsorption

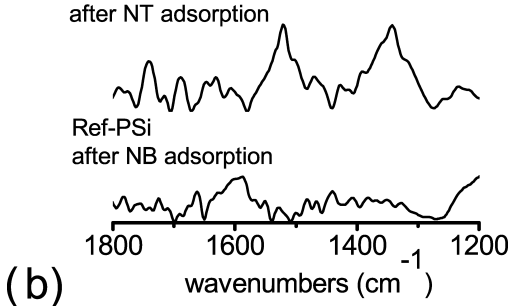

(b)

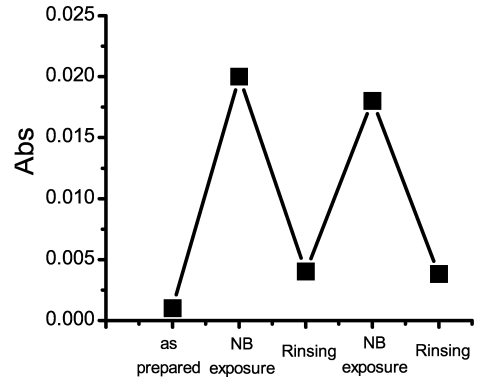

Figure 4. (a) FTIR spectra in the $1800-1200 \mathrm{~cm}^{-1}$ range of EtQxBox-PSi after exposure to NB (up) or NT (middle) vapors. The spectrum of Ref-PSi after NB exposure (bottom) has been added for reference. (b) Intensity variation of the $1523 \mathrm{~cm}^{-1}$ band of $\mathrm{NO}_{2}$ after cycles of absorption/desorption of NB with EtQxBox-PSi.

feature associated with the $\mathrm{NO}_{2}$ group down to a $20 \%$ of the maximum after the desorption step indicates that the process operates with good reversibility (Figure 4b).

The complexation process was also monitored by XPS. Figure 5 reports the $\mathrm{N}$ 1s spectral regions of EtQxBox-PSi (Figure 5a) and Ref-PSi (Figure 5b) before and after the complexation process with NB. After the exposure to NB, the $\mathrm{N}$ 1s region of EtQxBox-PSi (Figure 5a middle trace) shows a new broad peak at $\sim 406.0 \mathrm{eV}$, besides the typical peak at 399.9 $\mathrm{eV}$, attributable to the presence of the $\mathrm{NO}_{2}$ group of $\mathrm{NB}$ in the cavity. In the case of Ref-PSi, only the $\mathrm{N} 1 \mathrm{~s}$ band centered at $400.0 \mathrm{eV}$ assigned to the nitrogens of the 2,7-diamido-1,8naphthyridine is present before and after vapor exposure (Figure 5b).

The NB desorption induced by sample heating was also monitored by XPS analysis, confirming the process reversibility observed in the FTIR experiments (Figure 5a upper trace).

Nitroaromatic vs Aromatic Complexation at the GasSolid Interface. The complexation of benzene $\left(10^{4} \mathrm{~Pa}\right), \mathrm{NB}$ $(30 \mathrm{~Pa})$, and NT $(15 \mathrm{~Pa})$ vapors on EtQxBox-PSi slides and their thermal desorption under ultra-high vacuum (UHV) conditions (total pressure $=10^{-8}$ Torr) were studied by in situ mass spectrometry. Various ions associated with the fragmentation of the desorbing molecules have been detected by the mass spectrometer during the heating of the substrate (Figure 6). In the case of benzene desorption, the molecular $\mathrm{C}_{6} \mathrm{H}_{6}{ }^{+}$(main ion) ion and the $\mathrm{C}_{6} \mathrm{H}_{5}{ }^{+}$fragment $(<20 \%)$ start to desorb below $50{ }^{\circ} \mathrm{C}$, and the desorption is completed at about $150{ }^{\circ} \mathrm{C}$.

In the case of $\mathrm{NB}$, the complexation is proved by the desorption of the $\mathrm{C}_{6} \mathrm{H}_{5}{ }^{+}$fragment, which in this case is the most intense, whereas the observed molecular $\mathrm{C}_{6} \mathrm{H}_{5} \mathrm{NO}_{2}{ }^{+}$ion

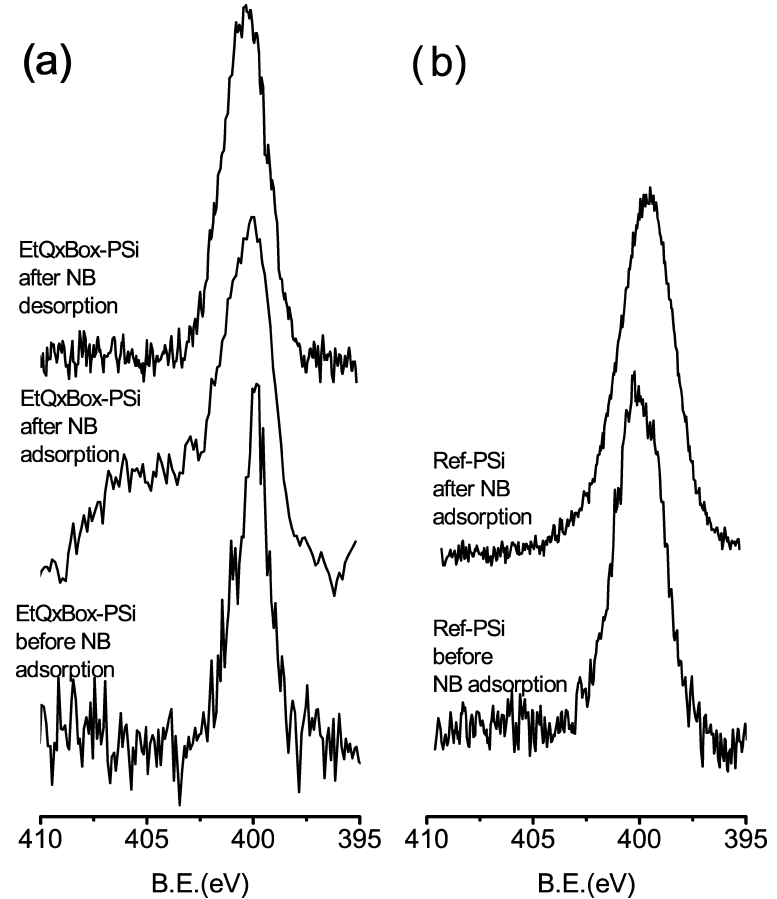

Figure 5. N 1s spectral regions of (a) EtQxBox-PSi and (b) Ref-PSi before and after the NB exposure.

is about $30 \%$ of the main fragment. Note that the desorption temperature range of $\mathrm{NB}$ is broader than the one observed for benzene. The same trend is observed for the thermal desorption of NT (Figure S4). Similar experiments performed on the inert Ref-PSi slides showed a minimal uptake of the guests, further confirming that the presence of the cavitand on the surface is essential for the aromatic compound complexation.

To evaluate the different affinities of EtQxBox-PSi toward aromatic and nitroaromatic compounds, a set of experiments with simultaneous adsorptions of vapors of $\mathrm{NB} /$ benzene (1:300 ratio) and of NB/toluene (1:100 ratio) was performed. The comparison between benzene and NB adsorption emphasizes the effects on the cavitand-arene complex if a nitro group is added to the aromatic ring. On the contrary, through experiments adopting toluene and NB mixtures, the role of the two substituents can be compared. After the adsorption of the benzene/ $\mathrm{NB}$ mixture, the main ions observed during the thermal desorption were $\mathrm{C}_{6} \mathrm{H}_{5}^{+}$, which is the most intense peak arising from NB fragmentation, and the $\mathrm{C}_{6} \mathrm{H}_{5} \mathrm{NO}_{2}{ }^{+}$molecular ion (Figure 7 ). Despite the large excess of benzene in the gas phase, only a reduced amount of benzene (peak $\mathrm{C}_{6} \mathrm{H}_{6}^{+}$) was released during heating. Note that the contribution of benzene to the intensity of the fragment $\mathrm{C}_{6} \mathrm{H}_{5}{ }^{+}$is below $10 \%$ because the amount of this ion, deriving from benzene fragmentation, is less than $20 \%$ of $\mathrm{C}_{6} \mathrm{H}_{6}^{+}$. This experiment has shown that NB is preferentially complexed with respect to benzene by $\mathrm{EtQxBox}-\mathrm{PSi}$. It therefore indicates that the addition of the nitro group to the aromatic ring increases the stability of the cavity-arene complex.

During thermal desorption after toluene/ $\mathrm{NB}$ exposure, the characteristic toluene ions (i.e., $\mathrm{C}_{7} \mathrm{H}_{8}{ }^{+}$e $\mathrm{C}_{7} \mathrm{H}_{7}{ }^{+}$) and the $\mathrm{NB}$ $\mathrm{C}_{6} \mathrm{H}_{5} \mathrm{NO}_{2}^{+}$and $\mathrm{C}_{6} \mathrm{H}_{5}^{+}$ions are clearly present.

Despite the excess of toluene in the gas phase, the amount of adsorbed NB is comparable to that of the adsorbed toluene, suggesting a higher affinity of EtQxBox toward NB. However, 

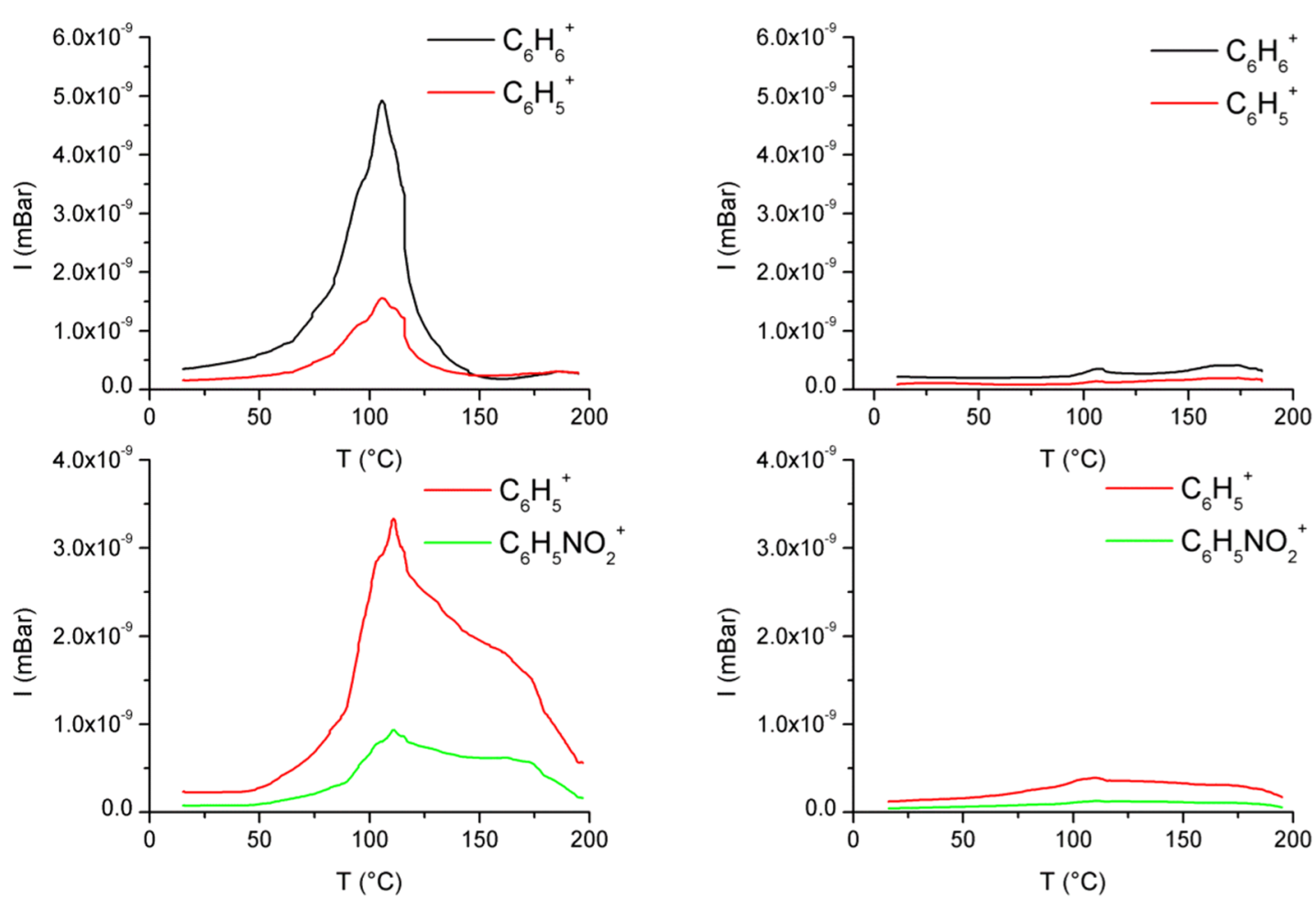

Figure 6. Thermal desorption experiments of EtQxBox-PSi (left) and Ref-PSi (right) after the adsorption of benzene (up) and NB (bottom).
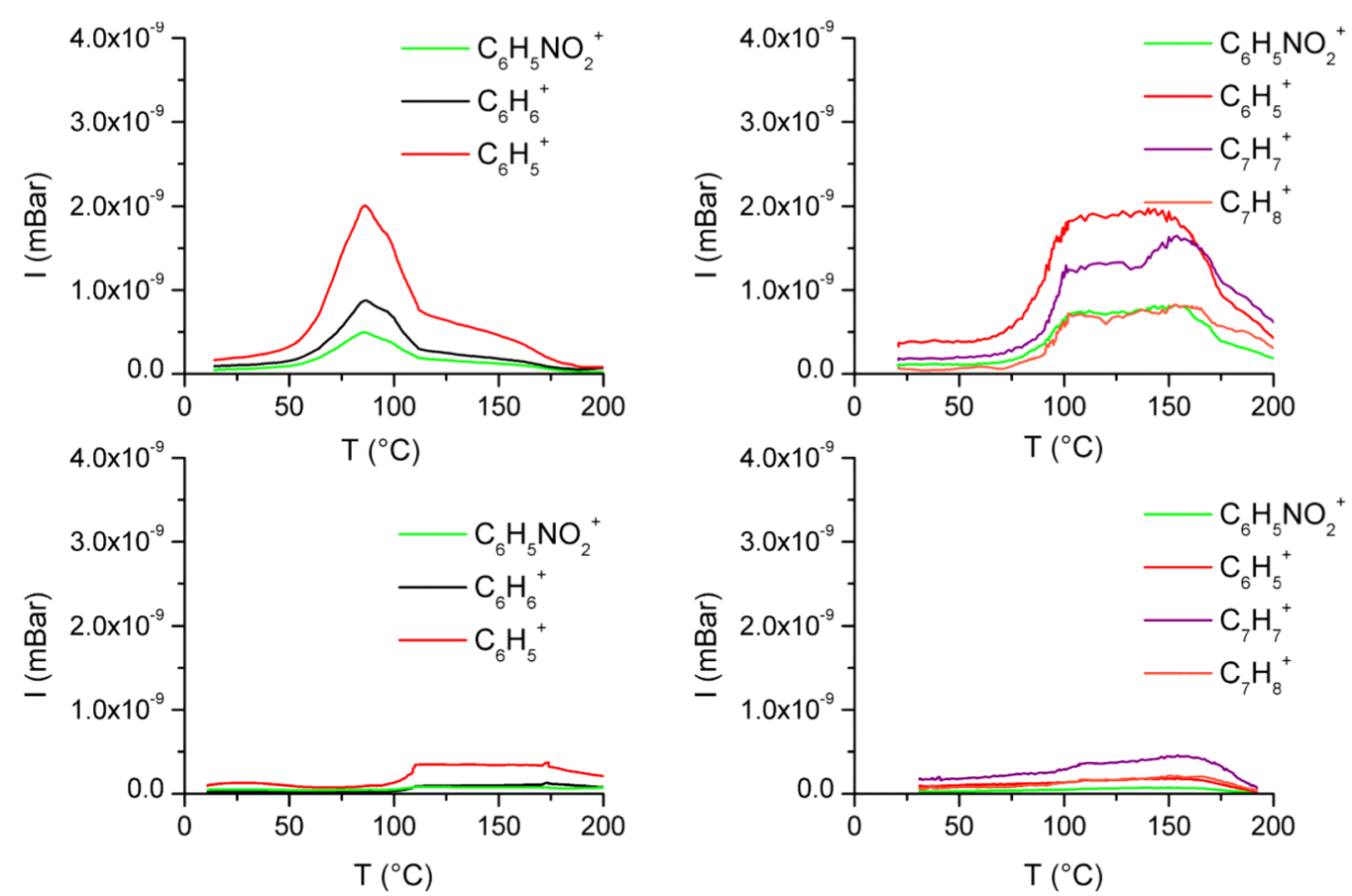

Figure 7. Thermal desorption experiments of EtQxBox-PSi (up) and Ref-PSi (bottom) after the adsorption of (left) benzene/NB (300:1) and (right) toluene/NB (100:1) mixtures.

in this case, the gap is less marked when compared to that of the benzene/NB mixture.

Rationalization of the Observed Selectivity via a DFT Study. DFT calculations of the insertion of aromatic compounds inside the EtQxBox cavity were performed to rationalize the higher affinity of the cavitand toward nitroaromatics compared to that toward simple aromatic hydrocarbons. In particular, complex formation with benzene, toluene, NB, and NT is compared. In all cases, deep insertion of the aromatic moiety into the cavity is observed (Figure 8).

Benzene and toluene insert deeper than the respective nitro derivatives (see also the corresponding crystal structures in ref 39). In the case of toluene, both orientations of the methyl group with respect to the cavity are energetically accessible, but the one with the methyl group protruding outside the cavity is 
(a)

(b)

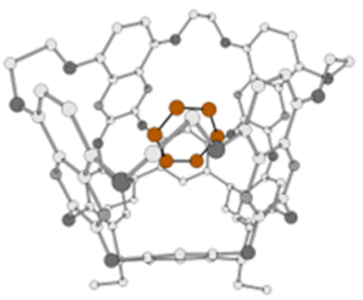

(c)

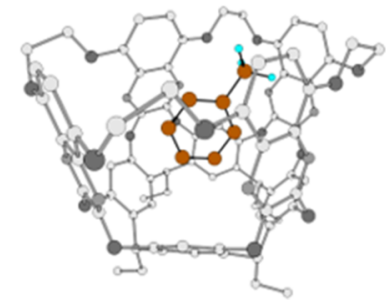

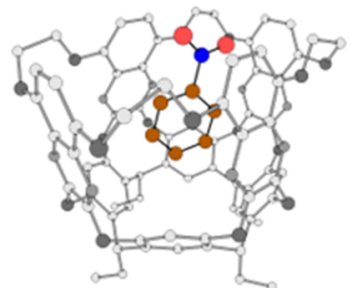

(d)

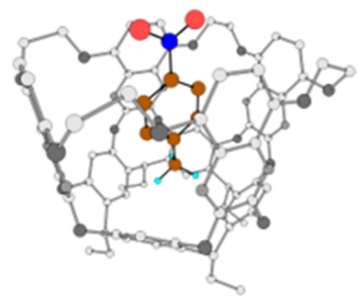

Figure 8. Optimized structures for the host-guest complex between aromatic guests and the EtQxBox cavitand: (a) benzene@EtQxBox; (b) NB@EtQxBox; (c) toluene@EtQxBox; and (d) NT@EtQxBox.

preferred (Figure $8 \mathrm{c}$ ). The nitro group is always positioned outside the cavity (Figure $8 \mathrm{~b}, \mathrm{~d}$ ).

The host-guest formation is in all cases exothermic and exoergonic (Figure 9). The stabilization energies are mostly

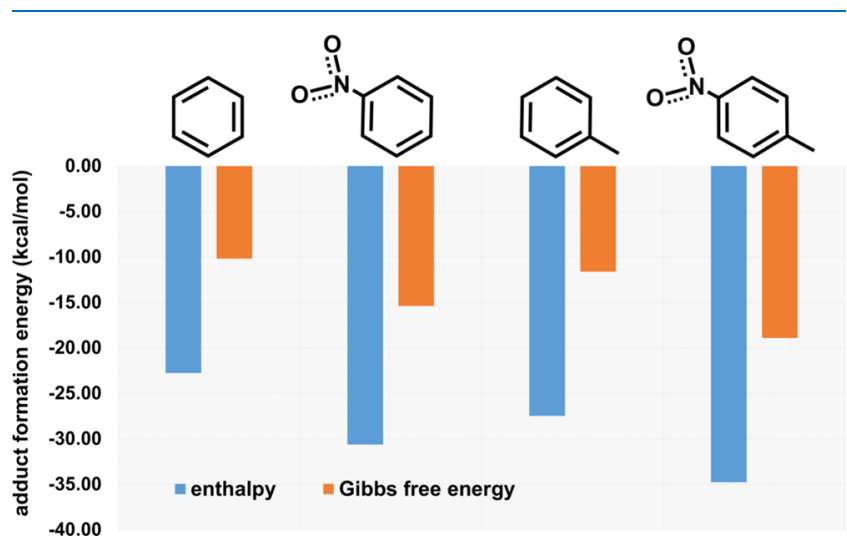

Figure 9. Interaction energy of the four guests with EtQxBox.

due to the $\mathrm{CH}_{\text {guest }} \cdots \pi_{\text {host }}$ and $\mathrm{CH}_{\text {guest }} \cdots \mathrm{N}_{\text {host }}$ interactions, as also evidenced by the NT@EtQxBox crystal structure. In the cases of NB and NT, a further stabilizing contribution of about 7 $\mathrm{kcal} / \mathrm{mol}$, compared to benzene and nitrobenzene, respectively, is ascribable to the dipole-dipole interaction between the nitroaromatics and EtQxBox (Figure S5). The much higher affinity of the cavity toward NB compared to benzene, observed in the adsorption/desorption experiments, is due to this difference. Smaller differences are observed in the adsorption affinity between NB and toluene, as confirmed by the calculated lower energy gap (about $3 \mathrm{kcal} / \mathrm{mol}$ ) between the host-guest complexes. In the case of toluene, the lack of the dipole-dipole stabilization due to the nitro group is partially balanced by the formation of the $\mathrm{CH}_{\text {guest }} \cdots \pi_{\text {host }}$ interactions of the methyl group. ${ }^{39}$ The process is entropy opposed due to the confinement of the guest inside the cavity. In fact, we found that Gibbs free energy values are always 13-

$16 \mathrm{kcal} / \mathrm{mol}$ higher than the respective enthalpy values (at 298 $\mathrm{K})$. The entropic loss is quantified in about $13-16 \mathrm{kcal} / \mathrm{mol}$ in the gas phase.

\section{CONCLUSIONS}

In this work, we report the synthesis, characterization, and complexation properties of a new organic-inorganic hybrid material based on a porous silicon surface decorated with a conformationally rigid quinoxaline-bridged cavitand. The recognition properties of EtQxBox toward aromatic VOCs have been transferred to the silicon surface. The success of the grafting protocol has been demonstrated by combining different analytic techniques (XPS and FTIR). Reversible host-guest complexation of aromatic and nitroaromatic compounds on the functionalized porous surface has been evaluated by XPS, FTIR, and desorption experiments. We demonstrated through the combination of experimental results and DFT modeling that the affinity of the EtQxBox-PSi system toward nitroaromatic compounds is significantly higher than the one toward benzene because of the stabilizing contribution due to the dipole-dipole interaction.

\section{EXPERIMENTAL SECTION}

Materials. Purchased chemicals were used as received unless otherwise noted. Water used in PSi preparation and functionalization was Milli-Q grade $(18.2 \mathrm{M} \Omega \mathrm{cm})$ and was passed as a final step through a $0.22 \mu \mathrm{m}$ filter.

Unless stated otherwise, reactions were conducted in flamedried glassware under an atmosphere of argon using anhydrous solvents (either freshly distilled or passed through activated alumina columns). Silica column chromatography was performed using silica gel 60 (Fluka 230-400 mesh or Merck 70-230 mesh). ${ }^{1} \mathrm{H}$ NMR spectra were obtained using a Bruker Avance $300(300 \mathrm{MHz})$ and a Bruker Avance 400 (400 $\mathrm{MHz})$ spectrometer at $298 \mathrm{~K}$. All chemical shifts $(\delta)$ were reported in $\mathrm{ppm}$ relative to the proton resonances resulting from incomplete deuteration of the NMR solvents. Highresolution matrix assisted laser desorption ionization-time of flight (MALDI-TOF) was performed on AB SCIEX MALDITOF-TOF 4800 Plus (matrix: $\alpha$-cyano-4-hydroxycinnamic acid). 2,3-Dicloro-5,8-dimethoxyquinoxaline $\mathrm{A}^{51}$ and undecylenic-footed resorcinarene Res $\left[\mathrm{C}_{10} \mathrm{H}_{19}, \mathrm{H}\right]^{44}$ (Scheme 1) were prepared according to published procedures.

Synthesis of Cavitand EtQxBox. Synthesis of Octametoxy-Quinoxaline Cavitand 1. First, $1 \mathrm{~g}\left(9.61 \times 10^{-4} \mathrm{~mol}\right)$ of resorcinarene Res $\left[\mathrm{C}_{10} \mathrm{H}_{19}, \mathrm{H}\right]$ was dissolved in $50 \mathrm{~mL}$ of dry $\mathrm{DMF} ; \mathrm{K}_{2} \mathrm{CO}_{3}(2.12 \mathrm{~g}, 0.01 \mathrm{~mol})$ and quinoxaline A (0.99 g, $\left.3.84 \times 10^{-3} \mathrm{~mol}\right)$ were then added. The reaction was conducted in a microwave reactor, in open-vessel modality, at $120^{\circ} \mathrm{C}$ for $1.5 \mathrm{~h}$. The crude was diluted in a large excess of ethyl acetate and washed with water. The organic phase was dried over sodium sulfate and evaporated. The compound was purified by flash column chromatography $\left(\mathrm{SiO}_{2}, \mathrm{CH}_{2} \mathrm{Cl}_{2}\right.$ / acetone 95:5-90:10), affording a yellow solid, active in fluorescence, in $69 \%$ yield. ${ }^{1} \mathrm{H} \mathrm{NMR}\left(\mathrm{CDCl}_{3}, 300 \mathrm{MHz}\right)$ : $7.43\left(\mathrm{~s}, 4 \mathrm{H}, \mathrm{H}_{\text {up }}\right), 6.93\left(\mathrm{~s}, 8 \mathrm{H}, \mathrm{ArH}_{\text {Quin }}\right), 6.84\left(\mathrm{~s}, 4 \mathrm{H}, \mathrm{H}_{\text {down }}\right)$, $5.79\left(\mathrm{~m}, 4 \mathrm{H},-\mathrm{CH}=\mathrm{CH}_{2}\right), 4.96\left(\mathrm{~m}, 8 \mathrm{H},-\mathrm{CH}=\mathrm{CH}_{2}\right), 4.02$ $\left(\mathrm{s}, 24 \mathrm{H},-\mathrm{OCH}_{3}\right), 3.95\left(\mathrm{t}, 4 \mathrm{H}, \mathrm{ArCH}-\mathrm{R}, J_{3}=7.9 \mathrm{~Hz}\right), 2.30$ (m, $\left.8 \mathrm{H},-\mathrm{ArCH}-\mathrm{CH}_{2}\right), 1.33\left(\mathrm{~m}, 56 \mathrm{H},-\mathrm{CH}_{2}-\right)$. MALDI: $m /$ $z=1787.89[\mathrm{M}+\mathrm{H}]^{+}$.

Synthesis of Tetraquinone-Quinoxaline Cavitand 2. Cavitand $1\left(1.02 \mathrm{~g}, 5.72 \times 10^{-4} \mathrm{~mol}\right)$ was dissolved in 100 
$\mathrm{mL}$ of tetrahydrofuran, and cerium ammonium nitrate $(3.76 \mathrm{~g}$, $6.86 \times 10^{-3} \mathrm{~mol}$, previously diluted in a minimum amount of water) was added. The mixture was stirred at room temperature for $30 \mathrm{~min}$ and then quenched by the addition of water. After extraction with ethyl acetate and evaporation, the compound was purified by flash column chromatography $\left(\mathrm{SiO}_{2}, \mathrm{CH}_{2} \mathrm{Cl}_{2}\right.$ /acetone 85:15), affording an orange solid in $80 \%$ yield. Owing to its poor stability, the compound was characterized only through ${ }^{1} \mathrm{H}$ NMR and immediately used for the next reaction. ${ }^{1} \mathrm{H}$ NMR $\left(\mathrm{CDCl}_{3}, 300 \mathrm{MHz}\right): 7.38(\mathrm{~s}, 4 \mathrm{H}$, $\mathrm{H}_{\text {up }}$ ), $7.18\left(\mathrm{~s}, 8 \mathrm{H}, \mathrm{ArH}_{\text {Quin }}\right), 6.80\left(\mathrm{~s}, 4 \mathrm{H}, \mathrm{H}_{\text {down }}\right), 5.80(\mathrm{~m}, 4 \mathrm{H}$, $\left.-\mathrm{CH}=\mathrm{CH}_{2}\right), 4.97\left(\mathrm{~m}, 8 \mathrm{H},-\mathrm{CH}=\mathrm{CH}_{2}\right), 3.63(\mathrm{t}, 4 \mathrm{H}$, $\mathrm{ArCH}-\mathrm{R}, \mathrm{J}_{3}=7.4 \mathrm{~Hz}$ ), $2.30\left(\mathrm{~m}, 8 \mathrm{H}, \mathrm{ArCH}-\mathrm{CH}_{2}-\right), 1.33$ (m, 56H, $-\mathrm{CH}_{2}-$ ).

Synthesis of Octahydroxy Quinoxaline Cavitand 3. Tetraquinone-quinoxaline cavitand $2\left(0.21 \mathrm{~g}, 1.26 \times 10^{-4}\right.$ mol) was dissolved in $6 \mathrm{~mL}$ of acetone. Zinc $(0.92 \mathrm{~g}, 0.01 \mathrm{~mol})$ and $0.5 \mathrm{~mL}$ of acetic acid were added in this order. The suspension was sonicated for $5 \mathrm{~min}$. The crude was filtered over celite, dissolved in ethyl acetate, and washed with water, until complete removal of acetic acid. After evaporation, the pure compound was obtained as a bright yellow solid in $90 \%$ yield. ${ }^{1} \mathrm{H}$ NMR (DMSO- $d_{6}, 400 \mathrm{MHz}$ ): 8.32 (s, 8H, ArOH), $8.10\left(\mathrm{~s}, 4 \mathrm{H}, \mathrm{H}_{\text {up }}\right), 7.90\left(\mathrm{~s}, 4 \mathrm{H}, \mathrm{H}_{\text {down }}\right), 6.94\left(\mathrm{~s}, 8 \mathrm{H}, \mathrm{ArH}_{\text {Quin }}\right)$, $5.83\left(\mathrm{~m}, 4 \mathrm{H},-\mathrm{CH}=\mathrm{CH}_{2}\right), 4.95\left(\mathrm{~m}, 8 \mathrm{H},-\mathrm{CH}=\mathrm{CH}_{2}-\right), 4.08$ $\left(\mathrm{t}, 4 \mathrm{H}, \mathrm{ArCH}-\mathrm{R}, J_{3}=7.3 \mathrm{~Hz}\right), 2.30\left(\mathrm{~m}, 8 \mathrm{H},-\mathrm{ArCH}-\mathrm{CH}_{2}-\right.$ ), $1.22\left(\mathrm{~m}, 56 \mathrm{H},-\mathrm{CH}_{2}-\right)$. MALDI-MS: $m / z=1673.71[\mathrm{M}+$ $\mathrm{H}]^{+}$.

Synthesis of Cavitand EtQxBox. Cavitand 3 ( $80 \mathrm{mg}, 4.78 \times$ $10^{-5} \mathrm{~mol}$ ) was dissolved in $5 \mathrm{~mL}$ of dry DMF in a microwave vessel. $\mathrm{Cs}_{2} \mathrm{CO}_{3}\left(202 \mathrm{mg}, 6.20 \times 10^{-4} \mathrm{~mol}\right)$ and ethylene glycol ditosylate $\left(106 \mathrm{mg}, 2.86 \times 10^{-4} \mathrm{~mol}\right)$ were added under nitrogen. The mixture was reacted in a microwave reactor at $120^{\circ} \mathrm{C}$ for $1.5 \mathrm{~h}$. The crude was extracted with $\mathrm{CH}_{2} \mathrm{Cl}_{2} / \mathrm{H}_{2} \mathrm{O}$, dried over sodium sulfate, and evaporated. The compound was purified by preparative thin layer chromatography $\left(\mathrm{SiO}_{2}\right.$, acetone $100 \%$ ), affording the desired compound as a bright yellow solid, in $50 \%$ yield. ${ }^{1} \mathrm{H} \mathrm{NMR}\left(\mathrm{CDCl}_{3}, 400 \mathrm{MHz}\right): 8.31$ $\left(\mathrm{s}, 4 \mathrm{H}, \mathrm{H}_{\text {up }}\right), 7.55\left(\mathrm{~s}, 4 \mathrm{H}, \mathrm{H}_{\text {down }}\right), 6.74\left(\mathrm{~s}, 8 \mathrm{H}, \operatorname{ArH}_{\text {Quin }}\right), 5.88$ $\left(\mathrm{m}, 4 \mathrm{H},-\mathrm{CH}=\mathrm{CH}_{2}\right), 5.81\left(\mathrm{t}, 4 \mathrm{H}, \mathrm{ArCH}-\mathrm{R}, J_{3}=7.6 \mathrm{~Hz}\right)$, $5.04\left(\mathrm{~m}, 8 \mathrm{H},-\mathrm{CH}=\mathrm{CH}_{2}\right), 4.64-4.50(\mathrm{~m}, 16 \mathrm{H}, \mathrm{Ar}-$ $\left.\mathrm{OCH}_{2} \mathrm{CH}_{2} \mathrm{OAr}\right), 2.11\left(\mathrm{~m}, 8 \mathrm{H},-\mathrm{ArCH}-\mathrm{CH}_{2}-\right), 1.32(\mathrm{~m}$, $\left.56 \mathrm{H},-\mathrm{CH}_{2}-\right)$. MALDI-MS: $m / z=$ calculated for $\mathrm{C}_{108} \mathrm{H}_{113} \mathrm{~N}_{8} \mathrm{O}_{16}[\mathrm{M}+\mathrm{H}]^{+}$1777.82745, found 1777.8230, calculated for $\mathrm{C}_{108} \mathrm{H}_{112} \mathrm{~N}_{8} \mathrm{NaO}_{16}[\mathrm{M}+\mathrm{Na}]^{+}$1799.8094, found $1799.8094[\mathrm{M}+\mathrm{Na}]^{+}$.

PSi Preparation. PSi has been prepared by wet metalassisted chemical etching according to a published method. ${ }^{39,40}$ In particular, Czochralski-grown, p-type $\mathrm{Si}(100)$ slides having a resistivity of $1.5-4 \Omega \mathrm{cm}$ were treated for $5 \mathrm{~min}$ with an hydrofluoric acid (HF) $(0.14 \mathrm{M})$ and $\mathrm{AgNO}_{3}\left(5 \times 10^{-4} \mathrm{M}\right)$ water solution. After the deposition of $\mathrm{Ag}$ particles, the slides were dipped in $\mathrm{HF}, \mathrm{H}_{2} \mathrm{O}_{2}$, and $\mathrm{H}_{2} \mathrm{O}\left(40 \% \mathrm{HF} / 30 \% \mathrm{H}_{2} \mathrm{O}_{2}\right.$ / $\mathrm{H}_{2} \mathrm{O}$ 25:10:4 v/v) solution for $1 \mathrm{~min}$ and then rinsed with Milli-Q water and dried under $\mathrm{N}_{2}$ flow.

Cavitand Grafting. For grafting on porous substrates, the etched PSi was dipped in a EtQxBox solution in mesitylene. The solution was refluxed at $200{ }^{\circ} \mathrm{C}$ under $\mathrm{N}_{2}$ for $5 \mathrm{~h}$; then functionalized PSi slides were cleaned by two washing cycles in an ultrasonic bath ( 5 min each) in dichloromethane.

Cavitand Complexation Tests. Adsorption experiments were performed by placing samples for $30 \mathrm{~min}$ in a closed chamber saturated with aromatic VOC vapors. The saturated chamber at $25{ }^{\circ} \mathrm{C}$ was obtained by placing one beaker (or two beakers for the mixtures) containing $3 \mathrm{~mL}$ of the aromatic compound (benzene, toluene, or NB) and allowing vapor saturation for $4 \mathrm{~h}$. The saturation of NT vapor was obtained by placing for $2 \mathrm{~h} \sim 50.0 \mathrm{mg}$ of NT in a closed chamber kept at 50 ${ }^{\circ} \mathrm{C}$.

Sample Characterization. XPS spectra were obtained with a PHI 5600 multitechnique ESCA-Auger spectrometer equipped with a monochromated $\mathrm{Al} \mathrm{K} \alpha \mathrm{X}$-ray source. Analyses were carried out with a photoelectron takeoff angle of $45^{\circ}$ (relative to the sample surface) with an acceptance angle of $\pm 7^{\circ}$. The XPS binding energy scale was calibrated by centering the C 1s peak due to hydrocarbon moieties and "adventitious" carbon at $285.0 \mathrm{eV}$.

FTIR spectra were obtained with JASCO FTIR 430, using 100 scans per spectrum (scan range 560-4000 $\mathrm{cm}^{-1}$, resolution $4 \mathrm{~cm}^{-1}$ ).

Thermal desorption experiments were performed in a UHV chamber (basic pressure $\sim 10^{-8}$ Torr). For the experiments, the holder (Vacuum Science, Italy) was resistively heated with a ramp of about $10{ }^{\circ} \mathrm{C} / \mathrm{min}$ from 30 to $200{ }^{\circ} \mathrm{C}$. The desorbed molecules were detected with a Smart-IQ + (Thermo Electron Corporation) quadrupole mass spectrometer equipped with an electron filament as ion source and a multiplier detector (mass range 1-300).

Crystal Structure of NT@EtQxBox. The crystal structure of NT@EtQxBox was determined by single-crystal X-ray diffraction methods. Intensity data and cell parameters were obtained at $190 \mathrm{~K}$ on a Bruker APEX II equipped with a charge-coupled device area detector and a graphite monochromator (Mo $\mathrm{K} \alpha$ radiation $\lambda=0.71073 \AA$ ). The data reduction was carried out using the SAINT and SADABS ${ }^{52}$ programs. The structure was solved by Direct Methods using SIR $97^{53}$ and refined on $F_{o}{ }^{2}$ by full-matrix least-squares procedures, using SHELXL-2014 $/ 7^{54}$ in the WinGX suite version 2014.1. ${ }^{55}$ All of the nonhydrogen atoms were refined with anisotropic atomic displacements, with the exclusion of some atoms belonging to the disordered DMSO lattice molecules and of a terminal methyl carbon atom of the alkyl chain. The hydrogen atoms were included in the refinement at idealized geometries ( $\mathrm{C}-\mathrm{H}$ 0.95/0.99 $\AA$ ) and refined "riding" on the corresponding parent atoms. The weighting schemes used in the last cycle of refinement was $w=1 /\left[\sigma^{2} F_{\mathrm{o}}^{2}+(0\right.$. $\left.0.1232 P)^{2}+5.6500 P\right]$, where $P=\left(F_{\mathrm{o}}{ }^{2}+2 F_{\mathrm{c}}{ }^{2}\right) / 3$. Geometric calculations were performed with the PARST97 program. $^{56}$ Crystallographic data (excluding structure factors) for the structure reported have been deposited with the Cambridge Crystallographic Data Centre as supplementary publication no. CCDC-1831062 and can be obtained free of charge on application to the CCDC, 12 Union Road, Cambridge, CB2 IEZ, U.K. (fax: +44-1223-336-033; e-mail deposit@ccdc.cam. ac.uk or http://www.ccdc.cam.ac.uk).

Computational Details. Calculations were performed adopting the M06 hybrid meta-generalised gradient approximation functional. ${ }^{57}$ The standard all-electron $6-31 \mathrm{G}^{* *}$ basis $^{58}$ was used for all atoms. Molecular geometry optimization of stationary points was carried out without symmetry constraints and used analytical gradient techniques. ${ }^{59}$ Frequency analysis was performed to obtain thermochemical information about the reaction pathways at $298 \mathrm{~K}$ using the harmonic approximation. All calculations were performed using the $\mathrm{G} 16$ code $^{60}$ on Linux cluster systems. 


\section{ASSOCIATED CONTENT}

\section{(S Supporting Information}

The Supporting Information is available free of charge on the ACS Publications website at DOI: 10.1021/acsomega.8b01018.

${ }^{1} \mathrm{H}$ NMR spectrum of the EtQxBox cavitand; crystallographic data, refinement details, and ORTEP view of NT@EtQxBox·10DMSO; crystallographic geometrical parameters and view of the host-guest interaction for the complex NT@EtQxBox; thermal desorption experiments for NT vapors; DFT calculated values of the dipole moment of the EtQxBox host and used guests (PDF)

\section{AUTHOR INFORMATION}

\section{Corresponding Authors}

*E-mail: enrico.dalcanale@unipr.it (E.D.).

*E-mail: guido.condorelli@unict.it (G.G.C.).

\section{ORCID}

Roberta Pinalli: 0000-0002-0000-8980

Enrico Dalcanale: 0000-0001-6964-788X

Guglielmo G. Condorelli: 0000-0001-6106-8875

\section{Present Address}

"Laboratory of Adsorption and Catalysis, Department of Chemistry, University of Antwerpen (CDE), Universiteitsplein 1, 2610 Wilrijk, Antwerpen, Belgium (C.T.).

\section{Notes}

The authors declare no competing financial interest.

\section{ACKNOWLEDGMENTS}

This work was supported by the European Union through the DOGGIES project (Grant FP7-SEC-2011-285446) and University of Catania through the project "Piano della Ricerca di Ateneo 2016-2018". Centro Interfacoltà di Misure "G. Casnati" and the "Laboratorio di Strutturistica Mario Nardelli" of the University of Parma are kindly acknowledged for the use of NMR and MALDI facilities and of the Diffractometer.

\section{REFERENCES}

(1) Bhatkhande, D. S.; Pangarkar, V. G.; Beenackers, A. C. M. Photocatalytic degradation of nitrobenzene using titanium dioxide and concentrated solar radiation: chemical effects and scaleup. Wat. Res. 2003, 37, 1223-1230.

(2) Rastogi, P. K.; Ganesan, V.; Krishnamoorthi, S. Palladium nanoparticles incorporated polymer-silica nanocomposite based electrochemical sensing platform for nitrobenzene detection. Electrochim. Acta 2014, 147, 442-450.

(3) Singh, S. Sensors-An effective approach for the detection of explosives. J. Hazard. Mater. 2007, 144, 15-28.

(4) Sarkar, P. K.; Prajapati, P. K.; Shukla, V. J.; Ravishankar, B.; Choudhary, A. K. Toxicity and recovery studies of two ayurvedic preparations of iron. Indian J. Exp. Biol. 2009, 47, 987-992.

(5) Lu, W.; Li, H.; Meng, Z.; Liang, X.; Xue, M.; Wang, Q.; Dong, X. Detection of nitrobenzene compounds in surface water by ion mobility spectrometry coupled with molecularly imprinted polymers. J. Hazard. Mater. 2014, 280, 588-594.

(6) Ewing, R. G.; Atkinson, D. A.; Eiceman, G. A.; Ewing, G. J. A critical review of ion mobility spectrometry for the detection of explosives and explosive related compounds. Talanta 2001, 54, 515529.

(7) Gares, K. L.; Hufziger, K. T.; Bykov, S. V.; Asher, S. A. Review of explosive detection methodologies and the emergence of standoff deep UV resonance Raman. J. Raman Spectrosc. 2016, 47, 124-141.
(8) Cao, X.; Shen, L.; Ye, X.; Zhang, F.; Chen, J.; Mo, W. Ultrasound-assisted magnetic solid-phase extraction based ionic liquid-coated Fe3O4@graphene for the determination of nitrobenzene compounds in environmental water samples. Analyst 2014, 139, 1938-1944.

(9) Jian, C.; Rudolf, W. R. Membrane for in situ optical detection of organic nitro compounds based on fluorescence quenching. Anal. Chim. Acta 1990, 237, 265-271.

(10) Tian, D.; Li, Y.; Chen, R.-Y.; Chang, Z.; Wang, G.-Y.; Bu, X.-H. A luminescent metal-organic framework demonstrating ideal detection ability for nitroaromatic explosives. J. Mater. Chem. A 2014, 2, 1465-1470.

(11) Caygill, J. S.; Collyer, S. D.; Holmes, J. L.; Davis, F.; Higson, S. P. J. Disposable screen-printed sensors for the electrochemical detection of TNT and DNT. Analyst 2013, 138, 346-352.

(12) Cho, F.-H.; Kuo, S.-C.; Lai, Y.-H. Surface-plasmon-induced azo coupling reaction between nitro compounds on dendritic silver monitored by surface-enhanced Raman spectroscopy. RSC Adv. 2017, 7, 10259-10265.

(13) Chou, A.; Jaatinen, E.; Buividas, R.; Seniutinas, G.; Juodkazis, S.; Izake, E. L.; Fredericks, P. M. SERS substrate for detection of explosives. Nanoscale 2012, 4, 7419-7424.

(14) Maduraiveeran, G.; Ramaraj, R. Potential Sensing Platform of Silver Nanoparticles Embedded in Functionalized Silicate Shell for Nitroaromatic Compounds. Anal. Chem. 2009, 81, 7552-7560.

(15) Nagarkar, S. S.; Joarder, B.; Chaudhari, A. K.; Mukherjee, S.; Ghosh, S. K. Highly Selective Detection of Nitro Explosives by a Luminescent Metal-Organic Framework. Angew. Chem., Int. Ed. 2013, 52, 2881-2885.

(16) Hu, Z.; Deiberta, B. J.; Li, J. Luminescent metal-organic frameworks for chemical sensing and explosive detection. Chem. Soc. Rev. 2014, 43, 5815-5840.

(17) Yuan, Y.; Wang, W.; Qiu, L.; Peng, F.; Jiang, X.; Xie, A.; Shen, Y.; Tian, X.; Zhang, L. Surfactant-assisted facile synthesis of fluorescent zinc benzenedicarboxylate metal-organic framework nanorods with enhanced nitrobenzene explosives detection. Mater. Chem. Phys. 2011, 131, 358-361.

(18) Levitsky, I. A.; Euler, W. B.; Tokranova, N.; Rose, A. Fluorescent polymer-porous silicon microcavity devices for explosive detection. Appl. Phys. Lett. 2007, 90, 041904-3.

(19) Zhang, Y.; Bo, X.; Nsabimana, A.; Luhana, C.; Wang, G.; Wang, H.; Li, M.; Guo, L. Fabrication of 2D ordered mesoporous carbon nitride and its use as electrochemical sensing platform for $\mathrm{H}_{2} \mathrm{O}_{2}$, nitrobenzene, and NADH detection. Biosens. Bioelectron. 2014, 53, $250-256$.

(20) Fowler, J. D.; Allen, M. J.; Tung, V. C.; Yang, Y.; Kaner, R. B.; Weiller, B. H. Practical Chemical Sensors from Chemically Derived Graphene. ACS Nano 2009, 3, 301-306.

(21) Bozic, R. G.; West, A. C.; Levicky, R. Square wave voltammetric detection of 2,4,6-trinitrotoluene and 2,4-dinitrotoluene on a gold electrode modified with self-assembled monolayers. Sens. Actuators, $B$ 2008, 133, 509-515.

(22) Apodaca, D. C.; Pernites, R. B.; Del Mundo, F. R.; Advincula, R. C. Detection of 2,4-Dinitrotoluene (DNT) as a Model System for Nitroaromatic Compounds via Molecularly Imprinted Short-AlkylChain SAMs. Langmuir 2011, 27, 6768-6779.

(23) Sun, X.; Wang, Y.; Lei, Y. Fluorescence based explosive detection: from mechanisms to sensory materials. Chem. Soc. Rev. 2015, 44, 8019-8061.

(24) Salinas, Y.; Martínez-Máñez, R.; Marcos, M. D.; Sancenón, F.; Costero, A. M.; Parra, M.; Gil, S. Optical chemosensors and reagents to detect explosives. Chem. Soc. Rev. 2012, 41, 1261-1296.

(25) Zyryanov, G. V.; Kopchuk, D. S.; Kovalev, I. S.; Nosova, E. V.; Rusinov, V. L.; Chupakhin, O. N. Chemosensors for detection of nitroaromatic compounds (explosives). Russ. Chem. Rev. 2014, 83, 783-819.

(26) Anzenbacher, P., Jr.; Mosca, L.; Palacios, M. A.; Zyryanov, G. V.; Koutnik, P. Iptycene-Based Fluorescent Sensors for Nitroaromatics and TNT. Chem. - Eur. J. 2012, 18, 12712-12718. 
(27) Mosca, L.; Koutník, P.; Lynch, V. M.; Zyryanov, G. V.; Esipenko, N. A.; Anzenbacher, P., Jr. Host-Guest Complexes of Pentiptycene Receptors Display Edge-to-Face Interaction. Cryst. Growth Des. 2012, 12, 6104-6109.

(28) Khasanov, A. F.; Kopchuk, D. S.; Kovalev, I. S.; Taniya, O. S.; Giri, K.; Slepukhin, P. A.; Santra, S.; Rahman, M.; Majee, A.; Charushina, V. N.; Chupakhin, O. N. Extended cavity pyrene-based iptycenes for the turn-off fluorescence detection of RDX and common nitroaromatic explosives. New J. Chem. 2017, 41, 2309-2320.

(29) Zampolli, S.; Betti, P.; Elmi, I.; Dalcanale, E. A supramolecular approach to sub-ppb aromatic VOC detection in air. Chem. Commun. 2007, 2790-2792.

(30) Bianchi, F.; Bedini, A.; Riboni, N.; Pinalli, R.; Gregori, A.; Sidisky, L.; Dalcanale, E.; Careri, M. Cavitand-Based Solid-Phase Microextraction Coating for the Selective Detection of Nitroaromatic Explosives in Air and Soil. Anal. Chem. 2014, 86, 10646-10652.

(31) Clément, P.; Korom, S.; Struzzi, C.; Parra, E. J.; Bittencourt, C.; Ballester, P.; Llobet, E. Deep Cavitand Self-Assembled on Au NPsMWCNT as Highly Sensitive Benzene Sensing Interface. Adv. Funct. Mater. 2015, 25, 4011-4020.

(32) Bertani, F.; Riboni, N.; Bianchi, F.; Brancatelli, G.; Sterner, E. S.; Pinalli, R.; Geremia, S.; Swager, T. M.; Dalcanale, E. TriptyceneRoofed Quinoxaline Cavitands for the Supramolecular Detection of BTEX in Air. Chem. - Eur. J. 2016, 22, 3312-3319.

(33) Aprile, A.; Ciuchi, F.; Pinalli, R.; Dalcanale, E.; Pagliusi, P. Probing Molecular Recognition at the Solid-Gas Interface by SumFrequency Vibrational Spectroscopy. J. Phys. Chem. Lett. 2016, 7, 3022-3026.

(34) Ryvlin, D.; Dumele, O.; Linke, A.; Fankhauser, D.; Schweizer, W. B.; Diederich, F.; Waldvogel, S. R. Systematic Investigation of Resorcin(4)arene-Based Cavitands as Affinity Materials on Quartz Crystal Microbalances. ChemPlusChem 2017, 82, 493-497.

(35) Pinalli, R.; Pedrini, A.; Dalcanale, E. Environmental Gas Sensing with Cavitands. Chem. - Eur. J. 2018, 24, 1010-1019.

(36) Moran, J. R.; Karbach, S. D.; Cram, J. Cavitands: synthetic molecular vessels. J. Am. Chem. Soc. 1982, 104, 5826-5828.

(37) Condorelli, G. G.; Motta, A.; Favazza, M.; Gurrieri, E.; Betti, P.; Dalcanale, E. Molecular Recognition of Halogen-Tagged Aromatic VOCs at the Air-Silicon Interface. Chem. Commun. 2010, 46, 288290.

(38) Tudisco, C.; Fragalà, M. E.; Giuffrida, A. E.; Bertani, F.; Pinalli, R.; Dalcanale, E.; Compagnini, G.; Condorelli, G. G. Hierarchical Route for the Fabrication of Cavitand-Modified Nanostructured $\mathrm{ZnO}$ Fibers for Volatile Organic Compound Detection. J. Phys. Chem. C 2016, 120, 12611-12617.

(39) Trzciński, J. W.; Pinalli, R.; Riboni, N.; Pedrini, A.; Bianchi, F.; Zampolli, S.; Elmi, I.; Massera, C.; Ugozzoli, F.; Dalcanale, E. In Search of the Ultimate Benzene Sensor: The EtQxBox Solution. ACS Sens. 2017, 2, 590-598.

(40) Chartier, C.; Bastide, S.; Lévy-Clément, C. Metal-assisted chemical etching of silicon in $\mathrm{HF}-\mathrm{H}_{2} \mathrm{O}_{2}$. Electrochim. Acta 2008, 53, 5509-5516.

(41) Jane, A.; Dronov, R.; Hodges, A.; Voelcker, N. H. Porous silicon biosensors on the advance. Trends Biotechnol. 2009, 27, 230239.

(42) Banglin, C.; Shengchang, X.; Qian, G. Metal-Organic Frameworks with Functional Pores for Recognition of Small Molecules. Acc. Chem. Res. 2010, 43, 1115-1124.

(43) D’Urso, A.; Tudisco, C.; Ballistreri, F. P.; Condorelli, G. G.; Randazzo, R.; Tomaselli, G. A.; Toscano, R. M.; Sfrazzetto, G. T.; Pappalardo, A. Enantioselective extraction mediated by a chiral cavitand-salen covalently assembled on a porous silicon surface. Chem. Commun. 2014, 50, 4993-4996.

(44) Thoden van Velzen, E. U.; Engbersen, J. F. J.; Reinhoudt, D. N. Synthesis of Self-Assembling Resorcin(4)arene tetrasulfide adsorbated. Synthesis 1995, 1995, 989-997.

(45) Tudisco, C.; Betti, P.; Motta, A.; Pinalli, R.; Bombaci, L.; Dalcanale, E.; Condorelli, G. G. Cavitand-Functionalized Porous
Silicon as an Active Surface for Organophosphorus Vapor Detection. Langmuir 2012, 28, 1782-1789.

(46) Mattei, G.; Valentini, V.; Yakovlev, V. A. An FTIR study of porous silicon layers exposed to humid air with and without pyridine vapors at room temperature. Surf. Sci. 2002, 502-503, 58-62.

(47) Buriak, J. M.; Stewart, M. P.; Geders, T. W.; Allen, M. J.; Choi, H. C.; Smith, J.; Raftery, D.; Canham, L. T. Lewis Acid Mediated Hydrosilylation on Porous Silicon Surfaces. J. Am. Chem. Soc. 1999, 121, 11491-11502.

(48) Tudisco, C.; Sfrazzetto, G. T.; Pappalardo, A.; Motta, A.; Tomaselli, G. A.; Fragalà, I. L.; Ballistreri, F. P.; Condorelli, G. G. Covalent Functionalization of Silicon Surfaces with a CavitandModified Salen. Eur. J. Inorg. Chem. 2011, 2124.

(49) Perry, R.; Green, D. W. Perry's Chemical Engineers' Handbook, 8th ed.; McGraw-Hill: New York, NY, 2007.

(50) Pedrini, A.; Poggini, L.; Tudisco, C.; Torelli, M.; Giuffrida, A. E.; Bertani, F.; Cimatti, I.; Otero, E.; Ohresser, P.; Sainctavit, P.; Suman, M.; Condorelli, G. G.; Mannini, M.; Dalcanale, E. SelfAssembly of $\mathrm{TbPc}$ Single-Molecule Magnets on Surface through Multiple Hydrogen Bonding. Small 2018, 14, No. 1702572.

(51) Riboni, N.; Trzcinski, J. W.; Bianchi, F.; Massera, C.; Pinalli, R.; Sidisky, L.; Dalcanale, E.; Careri, M. Conformationally blocked quinoxaline cavitand as solid-phase microextraction coating for the selective detection of BTEX in air. Anal. Chim. Acta 2016, 905, 7984.

(52) Bruker, APEX2, SAINT and SADABS; Bruker AXS Inc.: Madison, Wisconsin, 2008.

(53) Altomare, A.; Burla, M. C.; Camalli, M.; Cascarano, G. L.; Giacovazzo, C.; Guagliardi, A.; Moliterni, A. G. G.; Polidori, G.; Spagna, R. IR97: a new tool for crystal structure determination and refinement. J. Appl. Crystallogr. 1999, 32, 115-119.

(54) Sheldrick, G. M. A short history of SHELX. Acta Crystallogr., Sect. A: Found. Crystallogr. 2008, 64, 112-122.

(55) Farrugia, L. J. WinGX suite for small-molecule single-crystal crystallography. J. Appl. Crystallogr. 1999, 32, 837-838.

(56) Nardelli, M. Help for checking space-group symmetry. J. Appl. Crystallogr. 1996, 29, 296-300.

(57) Zhao, Y.; Truhlar, D. G. The M06 suite of density functionals for main group thermochemistry, thermochemical kinetics, noncovalent interactions, excited states, and transition elements: two new functionals and systematic testing of four M06-class functionals and 12 other functionals. Theor. Chem. Acc. 2007, 120, 215-241.

(58) Rassolov, V. A.; Pople, J. A.; Ratner, M. A.; Windus, T. L. 6 31G* basis set for atoms K through Zn. J. Chem. Phys. 1998, 109, 1223.

(59) Li, X.; Frisch, M. J. Energy-Represented Direct Inversion in the Iterative Subspace within a Hybrid Geometry Optimization Method. J. Chem. Theory Comput. 2006, 2, 835-839.

(60) Frisch, M. J. et al. Gaussian 16, Revision A.03; Gaussian, Inc.: Wallingford CT, 2016. 